Article

\title{
Unveiling the Relationship between the Use of Open Educational Resources and the Adoption of Open Teaching Practices in Higher Education
}

\author{
Fabio Nascimbeni *(D) and Daniel Burgos $(\mathbb{D}$ \\ Research Institute for Innovation \& Technology in Education (iTED), Universidad Internacional de La \\ Rioja (UNIR), Av. de la Paz, 137, 26006 Logroño, La Rioja, Spain; daniel.burgos@unir.net \\ * Correspondence: fabio.nascimbeni@unir.net
}

Received: 23 August 2019; Accepted: 10 October 2019; Published: 13 October 2019

\begin{abstract}
The goal of this paper is to advance the understanding of the way university educators currently adopt open educational practices (OEP) by analyzing the relation between the use of open educational resources (OER) and the implementation of open teaching practices. The results are based on data collected through an online survey among 724 university educators. Depending on the actual use of OER and open teaching practices by the survey respondents, we have categorized them along a scale that goes from "novice" to "expert", and we analyzed the data to evaluate their use of OER and their adoption of open teaching practices, looking for relationships between the two phenomena. The main finding of this paper, which confirms the latest research findings from the open education community, is that a strong relationship exists between the two dimensions: The more an educator uses OER, the more he will probably adopt open teaching practices, and vice versa. These results are discussed with a view to use this virtuous circle between the use of open content and adoption of open teaching as a way to build generalized open education capacity among universities' teaching staff.
\end{abstract}

Keywords: open educational resources; open teaching practices; higher education

\section{Introduction}

In the last decade, the concept of open educational practices (OEP) has raised interest within the open education movement [1]. Initially defined as practices "that are based on a competency-focused, constructivist paradigm of learning and promote a creative and collaborative engagement of learners with digital content, tools and services in the learning process" [2], the concept of OEP has been developing in both research and in daily educational practice [3] towards a broader understanding than teaching with OER [4]. For example, Cronin defines OEP as "a broad descriptor of practices that include the creation, use, and reuse of open educational resources (OER) as well as open pedagogies and open sharing of teaching practices" [3].

The open education community is converging in recognition of the potential of OER as a trigger to implement open pedagogies [5]. Much has been written on the innovation potential that the use of OER could have on the way educators teach, to the point of formalizing the concept of OER-enabled pedagogy, defined as teaching practices that take place "in the context of the $5 \mathrm{R}$ permissions (retain, reuse, revise, remix, and redistribute) which are characteristic of OER" [6]. The logic is simple: By replacing a proprietary set of learning materials with one that is openly licensed, educators can create new relationships between their learners and the knowledge they will be working with. When learners are encouraged to develop and meaningfully revise the teaching resources, the relationship between the teacher, the student, and the teaching content is inevitably transformed: knowledge converts from a stable asset (contained in a book, for example) into a fluid process in which students can actively 
and critically engage. The role of the teacher in this change process is key, since the possible openness level of every educator is deeply connected with their individual attitudes and culture [3], as well as the institutional context, since openness is a social construct where educators define their open practices and at the same time are defined by them [7]. However, the relation between the use of OER and the adoption of open teaching practices has not been studied in enough depth. In particular, research has not yet been able to demonstrate that OER adoption can be considered a gateway towards open pedagogy. This is a complex research problem, connected both with the difficulty of convincing educators to do things differently and with the different teachers' motivations for adopting OER. Some teachers might in fact be attracted to OER because of their potential for social justice, others by their impact on pedagogical innovation, others by both these drivers [8].

The goal of this paper is to contribute to improving the understanding of the correlation between the use of OER and the adoption of open teaching practices within higher education, as well as to investigate whether an inverse relationship also exists, where the use of open pedagogies is influencing the potential adoption of OER.

\section{Methodology}

The overall research question that has guided our work is the following: Is there a positive relationship between the use of open educational resources and the adoption of open teaching methodologies in the work of university educators? This question has been addressed by analyzing the relationship from two possible angles, resulting in two research subquestions:

RQ1: To which extent does the familiarity with and capacity of using open educational resources influence the adoption of open teaching approaches within the work of university educators?

RQ2: To which extent does the familiarity with and capacity of using open teaching approaches influence the use of open educational resources within the work of university educators?

The results are based on a dataset gathered through an online questionnaire that was answered by 921 university educators from around the globe, with 724 complete and therefore valid responses (78.61\%). Respondents came from 36 countries, the following being the most represented: Brazil (245 participants-33.83\%), Italy (190-26.24\%), Ireland (99-13.67\%), and Palestine (57-7.87\%). Data was collected during the period June 2016-May 2019 through an online service tool (the service tool is available at https://rd.unir.net/pub/oef/), available in English, French, Italian, Spanish, and Portuguese. The survey was disseminated through multiple means: by activating networks such as the Open Education Consortium and the European Distance and eLearning Network, by presenting the project at relevant conferences such as OER17 or OER18 or the UNESCO Second OER World Congress, and by promoting the existence of the survey through social media. It should be noted that the online questionnaire, which consisted of nine multiple choice questions, did not refer to concepts such as open educational resources or open educational practices, in order to avoid being perceived as an exercise for e-learning or open licensing specialists. In the questionnaire we refer to the use of "licences that makes the content openly available (such as Creative Commons)" to use a language that can be understood by educators without going too specific on the different existing licenses typologies in order to investigate the degree to which educators are open to openly licensed materials. The questionnaire is available in Appendix A.

For the purpose of the present work, we have adopted two clear definitions of OER and open teaching approaches. The OER definition we have used is the very recent one contained in the UNESCO Recommendation on OER: "Open educational resources (OER) are teaching, learning, and research materials in any medium that may be composed of copyrightable materials released under an open license, materials not protected by copyright, materials for which copyright protection has expired, or a combination of the foregoing" [9]. We have based our open teaching definition on the work of Stacey [10] and Reynolds [11]: Open teaching is about encouraging learners to access available online content, fostering co-creation of knowledge by students in collaboration with peers within and outside the university, and encouraging students to contribute to public knowledge resources. 
In our understanding, in contrast to the vision that understands open teaching as a further step of the openness journey that follows and enriches the use of OER, high degrees of open teaching can take place without the use of OER [12].

The collected data was analysed through the Open Educators Factory (OEF) framework, an approach that aims to facilitate the understanding of the different and interrelated dimensions of university educators' capacity to adopt OEP. The framework, presented in Table 1, was designed following an extensive literature review and subsequent discussions with a number of experts in the domain of open education [13]. The framework identifies four areas of educators' practice that can be enhanced by open approaches (Design, Content, Teaching and Assessment) and grades the ability of educators to adopt open approaches in these areas along three levels, that are represented by the three rows of the table below. Within the present paper, we have focussed on two central areas, which are Content and Teaching.

Table 1. The Open Educators Factory Framework.

\begin{tabular}{cccc}
\hline Design & Content & Teaching & Assessment \\
\hline Open designer & Expert OER user & Open teacher & Open evaluator \\
$\begin{array}{c}\text { Collaborative designer } \\
\text { Individual designer }\end{array}$ & Familiar with OER & Engaging teacher & Innovative evaluator \\
New to OER & Traditional teacher & Traditional evaluator \\
\hline
\end{tabular}

With respect to the use of open content (second column in Table 1), the framework typifies three categories of educators. Starting from the bottom of the table, we have the New to OER educators, who do not consider whether the resources they use are openly-licensed and who do not release their content under open licence, the Familiar with OER educators, who produce and share their resources under open licences and reuse resources recommended by trusted colleagues, and the OER experts, who search for and share resources through social media and repositories and who spread their resources beyond the classroom. In order to place the respondents into one of the three levels, we have used a data from combination of questions 2, 3, 4, 5, and 6, as detailed in Appendix A. The three educator typologies with regard to open teaching are presented in the third column of Table 1 and, starting from the bottom, are the Traditional teachers, who adopt conventional lecture-based pedagogy, the Engaging teachers, who complement traditional teaching with collaborative strategies and with innovative teaching methods such as the flipped-classroom approach, and the Open teachers, who foster students' knowledge co-creation and contribution to public knowledge resources. In order to place the respondents in one of the three levels we have used data obtained from question 7 , as detailed in Appendix A.

In order to appreciate the relation between the use of OER and the adoption of teaching practices, we have analyzed the data by distinguishing the three categories of respondents with respect to their scoring in the Content category (New to OER, Familiar with OER, and Expert OER user) and by assessing how each category scored in the Teaching category. Also, we have done the same by taking the three groups of respondents with respect to their scoring in the Teaching category (Traditional teacher, Engaging teacher, and Open teacher) and by assessing how respondents from each category scored in the Content category.

Two limitations of this study must be highlighted. First, the study was not able to consider the differences between the higher education systems and contexts of the country of origin of the survey respondents. This represents a limitation mainly because of the importance of contextual factors in the decision of whether to adopt open content and open pedagogies [3] and prevented us from running countries comparisons. Still, we believe that a common core set of activities exists across the globe regarding what university teachers do and how they do that, especially given the recent globalization trends in higher education [14]. Second, participation in the survey was voluntary, so teachers who are familiar with the use of information and communication technology (ICT) or OER or both would have been more likely to respond. Also, we are aware that quantitative self-reported data may not be 
sufficient to draw sound conclusions about educators' attitudes to openness and adoption of open approaches [7].

\section{Results}

The online questionnaire has generated plentiful data: In this paper we present a fraction of the results, focusing on the relation between the adoption of OER and the use of open teaching methods, in line with the research questions presented above.

\subsection{Use of Open Teaching Methods among Different Categories of OER Users}

First, it is useful to understand how respondents scored in terms of OER adoption. As shown in Figure 1, the studied population is rather strong in OER use, with only $15 \%$ of respondents categorized as New to OER, $42 \%$ categorized as Familiar with OER, and $43 \%$ categorized as Expert OER Users. This distribution is probably due to two things. First, most respondents likely had a vested interest in open education and OER given that $85 \%$ were at least familiar with OER. Second, in order to score as either Familiar or Expert OER user, it was sufficient to respond positively to either question 2, 3, or 4 (presented in Appendix A). As stated before, we selected not to adopt a strict definition of OER, based for example on the well-known $5 R$ paradigm [15] but rather to consider every educator that is working with open content (as described in questions 2, 3, and 4) as belonging to the category Familiar with OER.

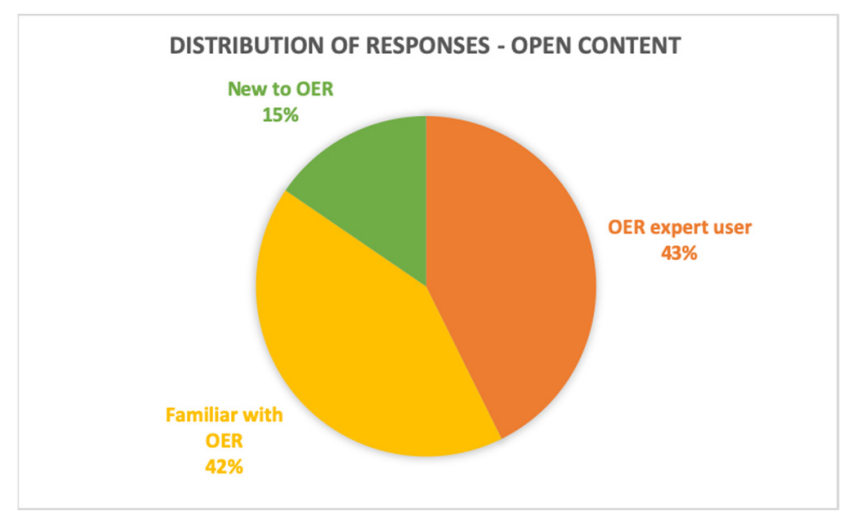

Figure 1. Distribution of respondents with respect to the use of open content.

We then analyzed the relation between the use of OER and open teaching approaches by looking at the actual shares of Traditional, Engaging, and Open teachers among the three different cohorts with respect to OER use, as in Figure 2.

The three graphs above show how the cohorts of OER experts (top-left), Familiar with OER (top-right), and New to OER (bottom) position with respect to open teaching. It suggests a relationship between the use of OER and the adoption of open teaching approaches, in that the share of Open teachers increases together with the capacity to use OER. The percentage of Open teachers is $40 \%$ for the OER Experts cohort, $13 \%$ for the Familiar with OER cohort, and 6\% for the New to OER cohort. Interestingly, the percentage of Engaging teachers that adopt collaborative and engaging methodologies but are not necessarily open in terms of reaching beyond the classroom does not vary significantly among the three cohorts. This could be due to the fact that these engaging strategies are not necessarily based on digital resources, as reflected by one of the possible answers to Question 5: "I use seminars-like strategies, either offline or through restricted online spaces", and therefore the use of OER might not be influencing the decision on whether to adopt those strategies or not. Interestingly, this shows an important pocket of innovation with a high potential in terms of open education, composed of those teachers that are adopting engaging teaching strategies without using OER (between $43 \%$ and $49 \%$ of respondents), and that due to their openness to innovation and willingness to experiment with new teaching methods could easily become proficient OER users. A final important finding is 
that, among OER Expert teachers, just $11 \%$ are using only traditional lecture-based teaching methods: This hints to the fact that investing in OER adoption, most probably due to their inner collaboration and engagement triggering capacity, can have an important impact on updating the teaching style of university educators.

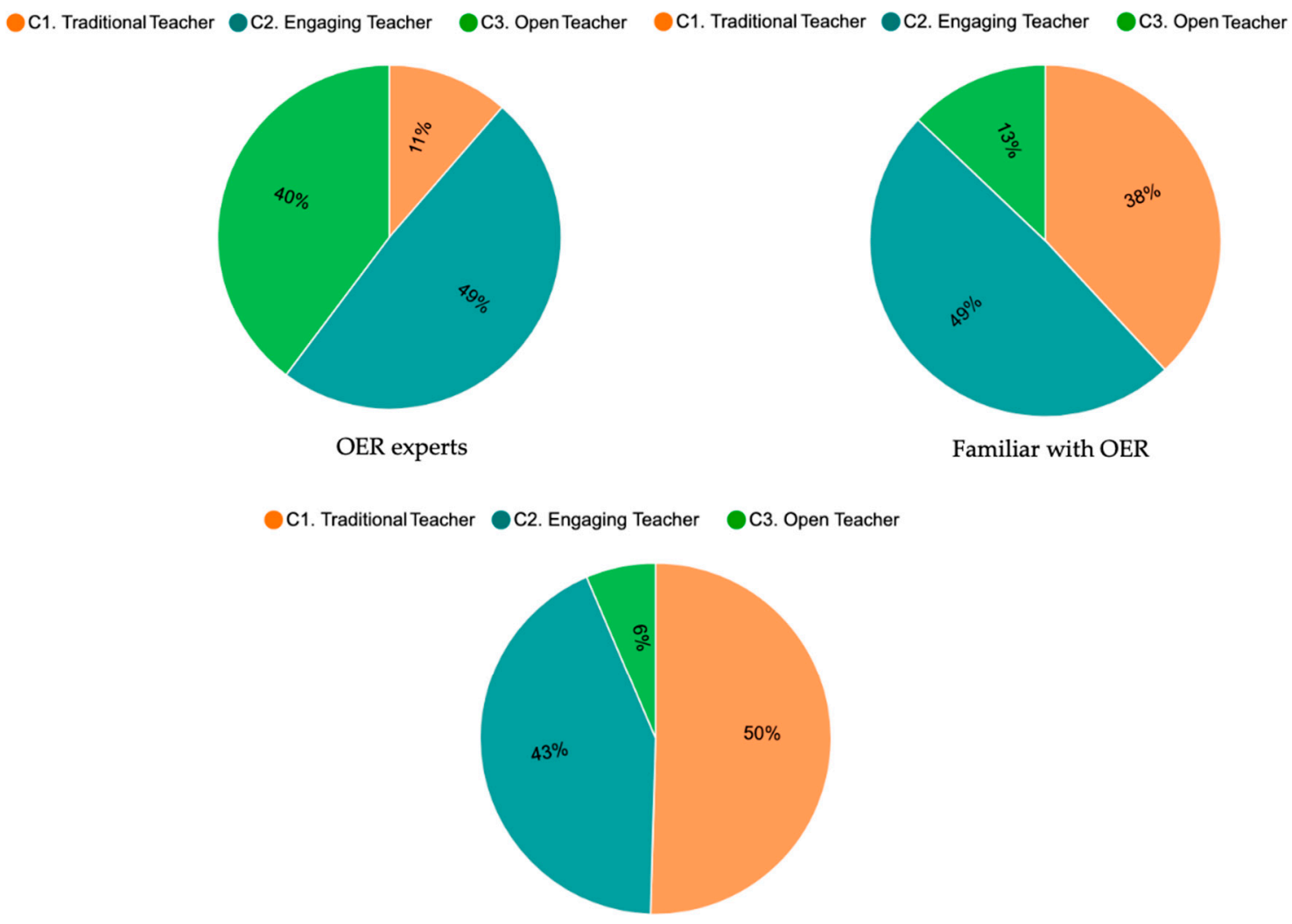

New to OER

Figure 2. To which extent do educators adopt open teaching approaches? Responses from OER experts (top-left), Familiar to OER (top-right), New to OER (bottom).

\subsection{Use of OER among Different Categories of Open Teachers}

Distribution of respondents across the three categories related to open teaching practices, presented in Figure 3, was based on the most common modality of teaching reported by participants: $28 \%$ use only one-way transmissive teaching methods and qualify therefore as Traditional teachers, $48 \%$ engage students through offline and online collaborative methods (Engaging teachers), while $24 \%$ foster co-creation of knowledge by students, working with wikis, blogs, and communities of practice and involve external stakeholders in the teaching process (Open teachers). 


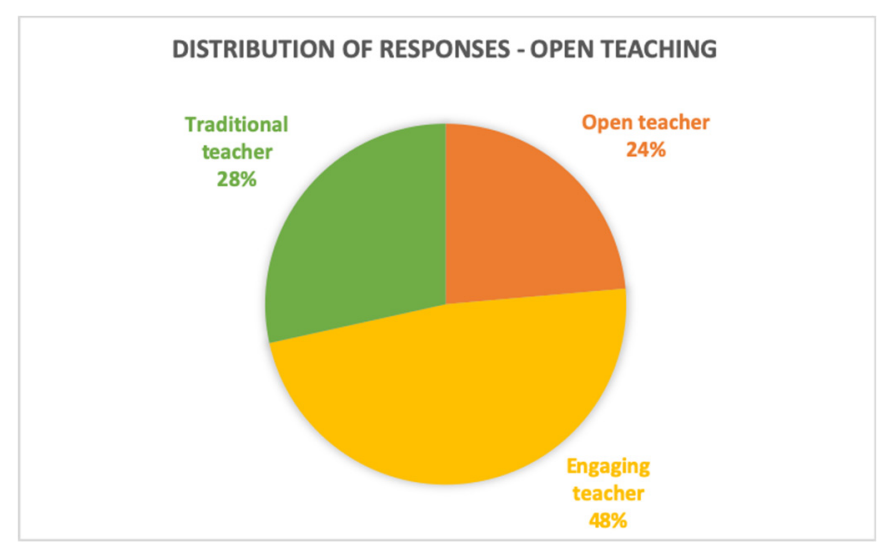

Figure 3. Distribution of respondents with respect to the use of open teaching approaches.

The three graphs of Figure 4 show the extent to which Open teachers (top-left), Engaging teachers (top-right), and Traditional teachers (bottom) qualify in terms of OER adoption.



Open teachers

\section{B1. New to OER \\ B2. Familiar with OER OB3. OER expert user}

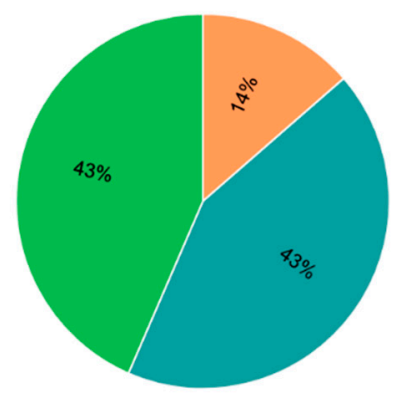

Engaging teachers
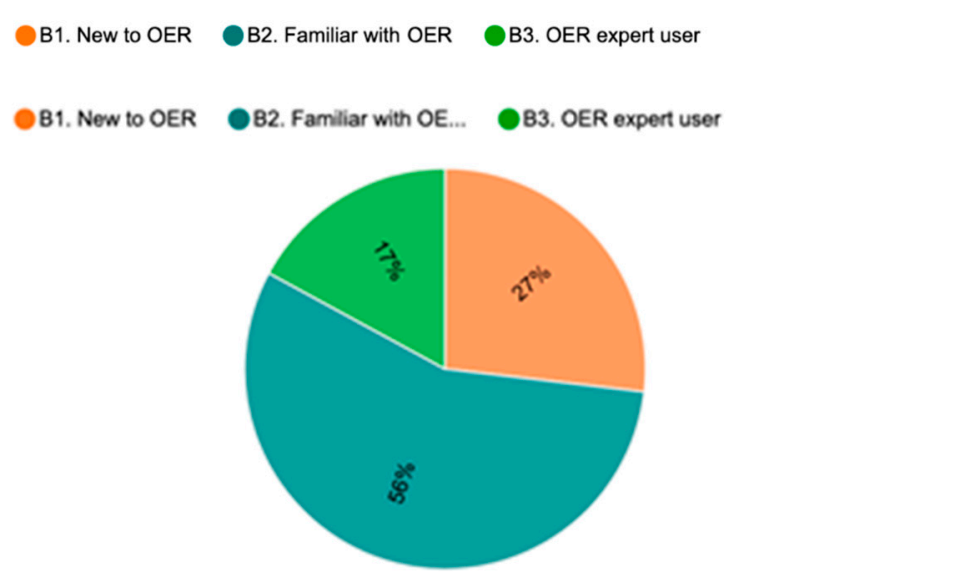

Figure 4. To which extent do educators adopt OER? Responses from Open teachers (above), Engaging teachers (middle), Traditional teachers (below).

Again, in this case, a positive relation emerges among the use of open teaching approaches and the tendency to adopt OER. This is demonstrated by the fact that among Open teachers, only $4 \%$ qualify as New to OER, while $73 \%$ are defined as Expert OER users. Open teaching approaches based on knowledge co-creation, which are adopted both by Open and Engaging teachers, normally encourage students to look for content on the open web, and to do so the educators must be able to guide students on where to search and especially on the strategies to use content produced by others. Interestingly, 
more than half of the Engaging teachers cohort are either Familiar with OER or OER Expert users, showing that the use of open content is strongly embedded within innovative pedagogies even when these are not going beyond the classroom setting. Finally, it is encouraging to see that among traditional educators, defined in the survey as teachers who use mainly frontal transmissive teaching, more than half of the respondents claimed to be at least Familiar with OER.

\section{Discussion}

Using relevant research findings with our results, we to try to deepen the understanding of the observed relational patterns between the use of open content and the adoption of open teaching practices. In contextual terms, it is important to notice that the open education community is increasingly moving towards research approaches that go beyond the analysis of open content adoption towards a broader understanding of the impact of open practices in support of innovative education [16]. However, only a limited number of studies have attempted to measure the proportion of teaching staff that adopt open practices. Further, most of these studies have been solely focusing on OER [17,18], with just a few addressing the use of open teaching methods [3,8].

First, a numerically relevant category of educators that are using OER in combination with open teaching practices has emerged from this study. Data presented in Figures 2 and 4 confirm that the use of open content and the adoption of open teaching tend to mutually reinforce, both at the level of educators that are both Expert OER users and Open teachers but also at the intermediate levels of educators that are fully open in one of the two dimensions (either content or teaching) and less in the other one. In all these cases, what can be observed is an agency shift from the teacher to the learners, who are considered independent agents within the learning process and are allowed to work independently and especially to learn at their own pace, in their own way and using their own personal networks [19]. In a context where learners have full access to ideas and resources that can shape and support their learning journeys, they deserve to be engaged in social processes of knowledge development instead of just being allowed to use the information presented by the teacher [20].

Second, the results show a relation between the use of OER and the attention to learners' collaboration dynamics. As shown by the possible responses of Question 7 in Appendix A, both Engaging and Open teachers are in fact using peer-to-peer pedagogies and group assignments over transmissive pedagogies. This finding corroborates the collaborative impact of OEP, intended as both use of open content and open teaching approaches, as concluded by Cronin who notes a relationship between the use of OEP and social learning practices [3]. Importantly, these collaborations can potentially empower students whether they work with OER within their classroom communities (with Engaging teachers) or by breaking down the university boundaries (with Open teachers), creating and/or curating content and contributing to public knowledge communities [4].

Also, the results show that within a university some educators might be more inclined to adopt open teaching strategies and might be using OER as a logical support for these approaches, while others might be more thoughtful in making sure that the content they use is made available openly, in line with institutional or national copyright legislation, and by doing so they use open resources that can potentially support social learning practices. The coexistence of these categories of educators corroborates the idea that, in order to increase the adoption of OEP within a university, multiple strategies are possible $[21,22]$. What matters here is that the data confirms that different roads can be taken to create sustainable ecosystems where OER can be used to support high-quality and inclusive education [5].

\section{Conclusions}

Based on the results presented above, we can conclude that a positive correlation exists between the use of OER, either at a level of familiarity or of high expertise, and the adoption of engaging and open teaching methods. By comparing these results with existing literature in the field [23,24], we can confirm that the combined use of open content and open teaching approaches can allow educators 
and students to build on the possibilities offered by the open web through collaborative knowledge creation, increased learning socialization, and interactivity and connection with communities outside the university. These results support a recent definition of OEP offered within a set of guidelines for educators by the Joint Research Centre of the European Commission, which understands OEP as teaching and learning practices that not only use OER but are also open to change, adaptations, and collaboration, making the range of different teaching and learning approaches more transparent, shareable, and visible. In this understanding, the use and reuse of OER goes hand in hand with the sharing of inclusive teaching strategies [25]. Finally, by looking at the relation between the use of OER and the adoption of open teaching methods from the point of view of those university leaders that want to increase the use of OEP within their institutions, open content appears as one of the key drivers for teaching innovation, and at the same time we can leverage educators' interest in new ways of teaching in order to foster the use of OER within universities.

Author Contributions: Article conceptualization, F.N. and D.B.; methodology, F.N. and D.B; investigation, F.N.; writing-original draft preparation, F.N.; review and editing, D.B.; conclusions, F.N. and D.B.

Funding: This research received no external funding.

Conflicts of Interest: The authors declare no conflict of interest.

\section{Appendix A Multiple-Choice Questionnaire}

(1) How do you design your lectures/courses?

a) On my own, based on my experience and knowledge, as I have always done. (result: individual designer)

b) In collaboration with colleagues from my institution. (result: collaborative designer)

c) In collaboration with colleagues from other institutions, through bilateral contacts. (result: collaborative designer)

d) I share ideas and drafts about my course through restricted social media (such as subject-related discussion groups) to allow colleagues from other institutions to contribute. (result: open designer)

e) I share ideas and drafts about my course through open social media (such as twitter, academia.edu, cloudworks), to allow anyone (including students) to contribute. (result: open designer)

(2) To whom do you make available your teaching resources (PPTs, documents)?

a) To students enrolled in my course, through the university website. (result: New to OER)

b) To all students of my university, through the university website. (result: Familiar with OER)

c) I make it openly available to anyone, through the university website. (result: Familiar with OER)

d) I make it openly available to anyone, through sharing platforms (Slideshare, repositories, etc). (result: OER Expert)

e) I also promote the content I produce through social media (such as Twitter, Slideshare, Facebook, Wikipedia ... ). (result: OER Expert)

(3) Under which licence do you release the teaching resources you produce?

a) I do not apply any licence, I just make it available to through the university website. (New to OER)

b) Through a restricted licence (all rights reserved). (result: New to OER)

c) Through a licence that makes it openly available (such as Creative Commons). (result: OER Expert) 
(4) Have you ever been using online resources (PPTs, videos, documents, articles) produced by others in your teaching? If so, under which license was this content released?

a) No, do not use online content produced by others in my teaching. (result: New to OER)

b) Yes. I am not worried about the license of these resources, since I used it for educational purposes. (result: Familiar with OER)

c) Yes. I only use resources released under an open licence, such as Creative Commons. (result: OER Expert)

(5) How did you get to know about these resources?

a) I have been searching for them on Google or other search engines. (result: New to OER)

b) Through a colleague from my university. (result: New to OER)

c) Through social media (such as Twitter, Slideshare, Facebook). (result OER Expert)

d) Through OER repositories. (result: Familiar with OER or OER Expert)

(6) Have you ever re-shared resources produced by others after using/adapting them?

a) No, never. (result: New to OER)

b) Yes, among colleagues from my university. (result: New to OER or Familiar with OER)

c) Yes, openly through social media (such as Twitter, Slideshare, Facebook). (result: Familiar with OER or OER Expert)

d) Yes, openly through OER repositories. (result: Familiar with OER or OER Expert)

(7) How do you teach?

a) I use classic, frontal classroom teaching. (result: Traditional Teacher)

b) I use the university Learning Management System (LMS) in support to classroom teaching, to share links and documents. (result: Traditional Teacher or Engaging Teacher)

c) I use seminars-like strategies, either offline or through restricted online spaces (Chats, forums). (result: Engaging Teacher)

d) I use "flipped-classroom" methodologies (using classroom time to discuss content that students have studies at home before the lesson). (result: Engaging Teacher)

e) I encourage my students to search for additional resources on the web and to produce their own knowledge. (result: Open Teacher)

f) I try to foster co-creation of knowledge by students by working with wikis, blogs, communities of practices. (result: Open Teacher)

(8) Do you encourage participation from non-enrolled students in your courser?

a) Yes (result: Open Teacher)

b) No (result: Traditional Teacher or Engaging Teacher)

(9) How do you assess your students?
a) I assess them through tests and classwork. (result: Traditional Evaluator)
b) I am introducing peers-assessment, either offline or through online means. (result: Innovative Evaluator)
c) My students have digital portfolios and are assessed through that. (result: Innovative Evaluator)
d) My students are assessed by online communities of Practices. (result: Open Evaluator) 


\section{References}

1. Bayne, S.; Knox, J.; Ross, J. Open education: The need for a critical approach. Learn. Media Technol. 2015, 40, 247-250. [CrossRef]

2. Schaffert, S.; Geser, G. Open Educational Resources and Practices. In Elearning Papers. Promoting Innovation in Lifelong Learning. Special Edition 2008; Carneiro, R., Tarin, L., Eds.; PAU Education: Barcelona, Spain, 2008; pp. 14-19.

3. Cronin, C. Openness and praxis: Exploring the use of open educational practices in higher education. Int. Rev. Res. Open Distrib. Learn. 2017, 18. [CrossRef]

4. Havemann, L. Open in the evening: Openings and closures in an ecology of practices. In Ecologies of Open; Conrad, D., Prinsloo, P., Eds.; Athabasca University Press: Athabasca, AB, Canada, forthcoming.

5. DeRosa, R.; Robison, S. From OER to Open Pedagogy: Harnessing the Power of Open. In Open: The Philosophy and Practices that are Revolutionizing Education and Science; Jhangiani, R.S., Biswas-Diener, R., Eds.; Ubiquity Press: London, UK, 2017; pp. 115-124. [CrossRef]

6. Wiley, D.; Hilton, J. Defining OER-Enabled Pedagogy. Int. Rev. Res. Open Distrib. Learn. 2018, 19. [CrossRef]

7. Veletsianos, G.A. case study of scholars' open and sharing practices. Open Prax. 2015, 7, 199-209. [CrossRef]

8. Jhangiani, R.S. Open as Default: The Future of Education and Scholarship. In Open: The Philosophy and Practices that are Revolutionizing Education and Science; Jhangiani, R.S., Biswas-Diener, R., Eds.; Ubiquity Press: London, UK, 2017; pp. 267-279. [CrossRef]

9. UNESCO. Recommendation on Open Educational Resources; UNESCO: Paris, France, forthcoming.

10. Stacey, P. The Pedagogy of MOOCs. Edtechfrontier.com. Available online: http://edtechfrontier.com/2013/05/ 11/the-pedagogy-of-moocs/ (accessed on 8 July 2019).

11. Reynolds, R. Eight Qualities of Open Pedagogies. Available online: https://nextthought.com/thoughts/2015/ 02/ten-qualities-of-open-pedagogy (accessed on 8 July 2019).

12. Hegarty, B. Attributes of Open Pedagogy: A Model for Using Open Educational Resources. Educ. Technol. 2015, 55, 3-13.

13. Nascimbeni, F.; Burgos, D. In search for the Open Educator: Proposal of a definition and a framework to increase openness adoption among university educators. Int. Rev. Res. Open Distrib. Learn. 2016, 17. [CrossRef]

14. de Wit, H. Globalisation and internationalisation of Higher Education. Int. J. Educ. Technol. High. Educ. 2011, 8, 241-248. [CrossRef]

15. Wiley, D. Defining the "Open" in Open Content and Open Educational Resources. Available online: https: //opencontent.org/definition/ (accessed on 11 October 2019).

16. Ferguson, R.; Barzilai, S.; Ben-Zvi, D.; Chinn, C.A.; Herodotou, C.; Hod, Y.; Kali, Y.; Kukulska-Hulme, A.; Kupermintz, H.; McAndrew, P.; et al. Innovating Pedagogy 2017: Open University Innovation Report 6; The Open University: Milton Keynes, UK, 2017.

17. Pete, J.; Mulder, F.; Dutra Oliveira Neto, J. Differentiation in Access to, and the Use and Sharing of (Open) Educational Resources among Students and lecturers at Kenyan Universities. Open Praxis 2017, 9, 173-194. [CrossRef]

18. Hilton, J.; Fischer, L.; Wiley, D.; Williams, L. Maintaining Momentum toward Graduation: OER and the Course Throughput Rate. Int. Rev. Res. Open Distrib. Learn. 2016, 17. [CrossRef]

19. Downes, S. Learning Networks in Practice. In Emerging Technologies for Learning; Ley, D., Ed.; BECTA: Coventry, UK, 2007.

20. Tuomi, I. Open Educational Resources and the Transformation of Education. Eur. J. Educ. 2013, 48, 58-78. [CrossRef]

21. Nascimbeni, F.; Burgos, D.; Campbell, L.M.; Tabacco, A. Institutional mapping of open educational practices beyond use of Open Educational Resources. Distance Educ. 2018, 39, 511-527. [CrossRef]

22. Bossu, C.; Willems, J. OER based capacity building to overcome staff equity and access issues in higher education. In Proceedings of the ASCILITE2017: 34th International Conference on Innovation, Practice and Research in the Use of Educational Technologies in Tertiary Education, Toowoomba, Australia, 4-6 December 2017; pp. 22-26.

23. Stracke, C.M. Quality Frameworks and Learning Design for Open Education. Int. Rev. Res. Open Distrib. Learn. 2019, 20, 180-203. [CrossRef] 
24. Weller, M.; Jordan, K.; DeVries, I.; Rolfe, V. Mapping the Open Education Landscape: Citation Network Analysis of Historical Open and Distance Education Research. Open Praxis 2018, 10, 109-126. [CrossRef]

25. Dos Santos, A.I. Practical Guidelines on Open Education for Academics: Modernising Higher Education via Open Educational Practices; (Based on the OpenEdu Framework), EUR 29672 EN; Publications Office of the European Union: Brussels, Belgium, 2019. [CrossRef] 